\title{
EVALUATING INNOVATIVE PROJECTS FOR AND WITH ELDERLY PEOPLE: INSIGHTS FROM PARTICIPATORY DESIGN CONTESTS
}

\author{
Jean, Camille (1); Cluzel, François (2); Vallet, Flore (2,3); Yannou, Bernard (2) \\ 1: Arts et Métiers ParisTech; 2: CentraleSupélec, Université Paris-Saclay; 3: IRT SystemX, Paris-Saclay
}

\begin{abstract}
Societies are challenged worldwide to maintain or improve the life of an ageing population. In the meantime, it is an opportunity for businesses to develop products and services for the elderly. Participatory design - or co-design - promotes not only to design for, but also with and by older adults. Current studies tend to emphasize more field investigations and co-ideation than evaluation of codesigned outcomes with seniors. We are interested in two 24 hours-innovation contests in 2017 and 2018, yearly involving 10 teams of 3 students, elderly persons as potential beneficiaries and innovation experts. The aim of this paper is to analyse the variability of evaluation of generated projects between the elderly people and the innovation experts. The comparative analysis relies on the grades and ranking of projects against five criteria. Results show that elderly people provide consistent evaluations, but with a positioning slightly shifted compared to the experts. We conclude on recommendations for the evaluation process with a jury including seniors.
\end{abstract}

Keywords: Innovation, Participatory design, User centred design, Design for elderly, Innovative projects evaluation

\section{Contact:}

Jean, Camille

École nationale supérieure d'arts et métiers (ENSAM)

LCPI

France

camillejean@ensam.eu 


\section{INTRODUCTION}

According to the World Health Organisation, between 2015 and 2030, the number of elderly people (aged 60 years or over) in the world is projected to grow by 56\%, from 901 million to more than 1.4 billion (World Health Organisation, 2015). It will be a challenge to maintain and improve the health and life condition of those people, but it will be also a great opportunity for industrialists to propose an adapted offer. This industrial sector is called Silver Economy (Zsarnoczky, 2016). It impacts several industries such as home accommodation, transport, food industry, insurance, robotics, health, sports and leisure. The Silver Economy is therefore driven both by the emergence of new consumer markets for products and services tailored to the ageing population and by the need to improve the sustainability of public expenditure linked to ageing (European Commission, 2015). Many companies are embedding "ageing" as a key strategic driver of their commercial goals. According to Euromonitor, the spending power of the now elderly "baby boomer" generation will reach $\$ 15$ trillion worldwide by 2020 (Euromonitor, 2012).

In France, it is now stated that 20 million people are 55 years old or more, representing $31 \%$ of the French population (INSEE, 2014). Among these segments of "seniors", 83\% are fully autonomous, while $7 \%$ are dependent and $10 \%$ are weakened. These two last categories require the aid of third parties to perform their daily activities, whatever they are familial or professional caregivers (Silver Valley, 2018). Although dependent and weakened elderly people need specialized products and services, most elderly people are looking for common goods and services. Innovating for the elderly people is thus not anymore dealing with healthcare, but more generally to well-being, or "wellageing". Lots of companies (from start-ups to large multinational firms) are now seizing these new market opportunities for developing offers for the elderly.

In order to ensure products and services that are adapted to the seniors' needs, including users - here elderly people and the associated stakeholders of their ecosystem - in the loop is essential. Usercentred design, where users are subjects, has recently evolved toward participatory or co-designing approaches (Sanders and Stappers 2008). Designing for people includes now designing with people (where users are active participants in the design process) and designing by people (where designers help users to become design actors). Different initiatives have emerged recently to include elderly people in the design process. Silver Valley, for instance, is a French cluster of more than 300 small and large companies, associations or public, research or education institutions which aims at developing the silver economy. It is probably the largest European cluster in healthcare. Silver Valley proposes each year several activities for helping companies to design useful products and services by including a panel of seniors, such as pitch sessions, living labs, or a yearly student challenge, which is the object of the present paper. In this 24-hour design challenge, 10 groups of 3 students, from different educational backgrounds, design from scratch an innovative product or service that is finally evaluated by a jury composed of innovation experts and seniors themselves. The jury members are asked to assess the 10 projects using a predefined grid adapted from the UNPC model (Yannou et al., 2017), an innovativeness set of indicators particularly adapted to creating utility for users. However, the two colleges of jury members have different skills and aims. The innovation experts are able to assess an innovative offer in its globality, and in particular its potential to meet success on the market; on the other hand, the panel of seniors represents potential future users of the concepts proposed by the students; but they are not only seniors, as they have, for most of them, accomplished a successful professional career before retiring.

This paper is a first attempt to analyse the evaluation phase of innovative projects by a jury including elderly people as representatives of potential users. The aim of the paper is to observe and analyse the variability of preferences and ranking of projects between the elderly people themselves and in comparison with the evaluations provided by the innovation experts. The authors propose some findings about the relevance of including such users in an evaluation jury; they provide some recommendations and findings for future juries.

Section 2 proposes a literature review divided in three subsections, where an overview of user-centred approaches is given, before focusing on how to include the elderlies in the loop; the last topic deals with the evaluation of innovative projects. After clarifying the positioning and the research question of the paper, Section 3 explains the case study of the "Silver Awards" innovative projects contest. Section 4 displays 
the methodology proposed to analyse the results further explained in section 5. A short discussion and some recommendations are proposed in section 6 before concluding in section 7 .

\section{LITERATURE BACKGROUND}

In this section, three main literature areas are explored. After describing the roles of people in design, and more specifically in participatory or co-design approaches, we develop specific examples of codesigning projects involving elderly people in different stages, notably in the evaluation of projects. Taking the innovation and creativity lens, insights on the evaluation of innovative projects are provided in 2.3. This leads to the research question presented in 2.4.

\subsection{Designing for, with and by people}

Sanders and Stappers (2008) stress that design research has shifted from a user-centred approach, where users are subjects, to a participatory or co-designing approach, where users are becoming partners of the process. In this context, users play a co-creating role in the design process at different levels of creative involvement, while the researcher becomes a facilitator for the expression of users' creativity (Sanders and Stappers, 2008). In participatory design, end-users indeed participate not only as evaluators of products, but also as active co-designers (Buur and Matthews, 2008). Combining usercentered innovation and participatory design, Buur and Matthews (2008) proposed a participatory innovation approach with a pool of technicians and managers split into five stages: field study, sensemaking, co-ideation, business modelling and co-design. Their aim was to investigate opportunities for novel products to control wastewater treatment processes, and solutions were co-designed on-site with technicians and managers (Buur and Matthews, 2008). Participatory design has been applied in various contexts of application. For instance, the design of medical digital support with and for ill children (Ruland, Starren and Vatne, 2008), the co-design of agricultural devices with farmers in Zambia (Brubaker et al., 2017) or the co-design experiences with poor people (Jagtap, 2018).

More specifically, dealing for and with elderly people, we can mention research works on co-design of transportation solutions (Wallisch et al., 2018), digital services (Wikberg-Nilsson et al.; 2018), daily joy and pain points of older adults in various situations (Shore et al., 2017). The contributions are developed in the next sub-section.

\subsection{Including elderly people in the loop}

Wikberg-Nilsson et al. (2018) report a participatory design approach with a focus group of five elderly people to design a digital service aiming at the improvement of their well-being and health. In order to evaluate the two co-created digital prototypes:

- The experts state about the utility or the appropriateness in use. Five key themes important for elderly people are emphasized, namely keeping family together, enjoying life at home, being close to nature, self-development and promotion conditions for healthy ageing;

- The elderly participants verbalize their experience by choosing words in a predefined list of adjectives.

Shore et al. (2017) report an ethnographic study involving designers (students and researchers) and 22 elderly participants, addressing unmet needs in the field of mobility, public spaces, safety, social engagement, and services \& facilities. After five weeks of fieldwork in the elderly homes, pieces of evidence on joy and pain points were gathered. The empirical material was exploited in a co-design workshop, where groups of ten people were facilitated by designers. The 10 co-designed projects were evaluated during a pitch session where judges (experts and seniors) voted for their preferred projects with stickers, but also "voted with their feet" (Shore et al., 2017).

In Wallisch et al. (2018), ten elderly people were involved in a participatory concept development of a tricycle along with four post-doctoral students. A focus group on lifestyles and problems about cycling was first conducted, provided that 6 out of the 10 participants stopped cycling due to an accident or a decline in their health. Several solutions were co-designed, and eventually the elderly were asked to evaluate the digital mock-up of the tricycle concepts.

\subsection{Assessing innovative projects}

Assessing creativity is a field that has been steadily explored in the literature, however most of the works are focusing on the efficiency of the creativity process (see for example the seminal paper by 
Shah et al. (2003)) more than the outcome of this process, i.e. the innovative concept, product or service. To assess the outcome, the concept of innovativeness metrics has been introduced, i.e. metrics to assess the economic success of an entrepreneurial or intrapreneurial venture, or, in other words, to assess the likelihood, at any stage of maturity, of an idea or a project becoming a successful innovation (Yannou et al., 2017). Whatever the context of this evaluation is (innovation incubator selection committees, internal R\&D funding committees or, in our case, student competitions), evaluating innovation requires metrics adapted to the purpose of the evaluation. Introducing assessors who are not innovation experts, for example elderly people, requires particularly simple and easy-to-use indicators while keeping the process relevant and scientific.

In the case of crowd innovation contests for example, the evaluation of ideas is conducted online. Klein and Garcia (2014) introduce the "bag of lemons" method, showing that is it easier for contest participants to filter out bad ideas among a large sample of propositions than pointing out wining ideas; however, the ideas are rejected without considering any specific evaluation criteria.

Dean and Santanen (2006) highlight from the analysis of 90 papers in the field of creativity that novelty, workability (feasibility), relevance (applicability and effectiveness for the identified problem) and specificity represent the quality measures of the idea generation process. IDEO introduces the set of desirability, feasibility and viability indicators to design human-centred innovation (IDEO, 2015). The "wow effect" is another indicator defined as a measure of users' feedback and acceptance (Boatwright and Cagan 2010). An exploration of the innovation marketing and business management literature brings more business-oriented indicators; Cooper and Astebro (Cooper 2001, Astebro 2004) for instance consider that the best predictors of new product success and profitability are defined by the potential to reach the right market rather than simply being creative. Cooper particularly highlights usefulness, usage newness and the user's desire to purchase a product (Cooper, 2001).

Yannou et al. (2017) propose a structured set of innovativeness indicators called the UNPC model and standing for Usefulness (coverage of frequent usage situations and the alleviation of users' pain), Newness (technical newness, possibly patentable; newness that customers or end-users value; real usage or technical newness), Profitability (economic profitability for both company and customers), proof of Concept (technological and industrial feasibility as well as the fact that a design solution has to function in expected usage situations). The UNPC model is the basis of the assessment grid used during the student contest presented in this paper (see Section 3), however it has been adapted by the organizers of the contest to be easily understandable by non-expert jury members in a short time.

\subsection{Positioning and research question}

In the literature review, we observed that the sampled current co-design studies tend to emphasize more field investigations and co-ideation than the evaluation of co-designed outcomes with seniors. Hence, there seems to be a gap in the characterization of criteria and processes for the assessment phase. Conversely, the innovation and creativity field provides a rich description of methods and criteria suitable for assessing innovative projects. However, the referenced works do not particularly consider elderly people in the loop.

In the case of innovation contests, the objective of the evaluation step is to select the ideas that are most likely to provide value for seniors and at the same time to offer opportunities for businesses. It is hence important to know if seniors and innovation experts have similar or dissimilar preferences. Our research question is formulated as follows: "In an innovation contest, is there a difference in the evaluation of innovative projects by seniors and innovation experts?" By answering this question, the authors try to give first insights for a broader reflexion on how to integrate seniors in an evaluation process alongside with innovation experts.

\section{CASE STUDY}

In order to answer to this research question, we base our study on the two last editions of the "Silver Awards", organized in Paris since 2016.

The Silver Awards is a student design challenge and an opportunity for 30 students each year to work in groups of 3 on a creative and innovative solution that concerns the improvement of seniors' life. The students are coming from different academic backgrounds: engineering, business schools, industrial design faculties, but also in lower proportions law, administration, medicine, communication. The student teams are mandatorily composed of different skills. 
Within 24 hours, the students choose a thematic (table 1), develop an innovative offer, and pitch their solution to a jury composed of experts and seniors. A coach and different experts in marketing, innovation management, design engineering, communication, financing, distribution, entrepreneurs, silver economy and sociology help them during the 24 hours. The coaches are not members of the final jury. The results can be products, services or activities and should be dedicated to seniors. At the end of the projects development, an evaluation is organized to rate the project and select the best ones. Other experts and some seniors take part of the jury (see composition in Table 1). The winning teams win gifts and the opportunity to develop further their ideas with the help of professionals. The detailed process of the Silver Awards 2018 held in November is given in Figure 1.

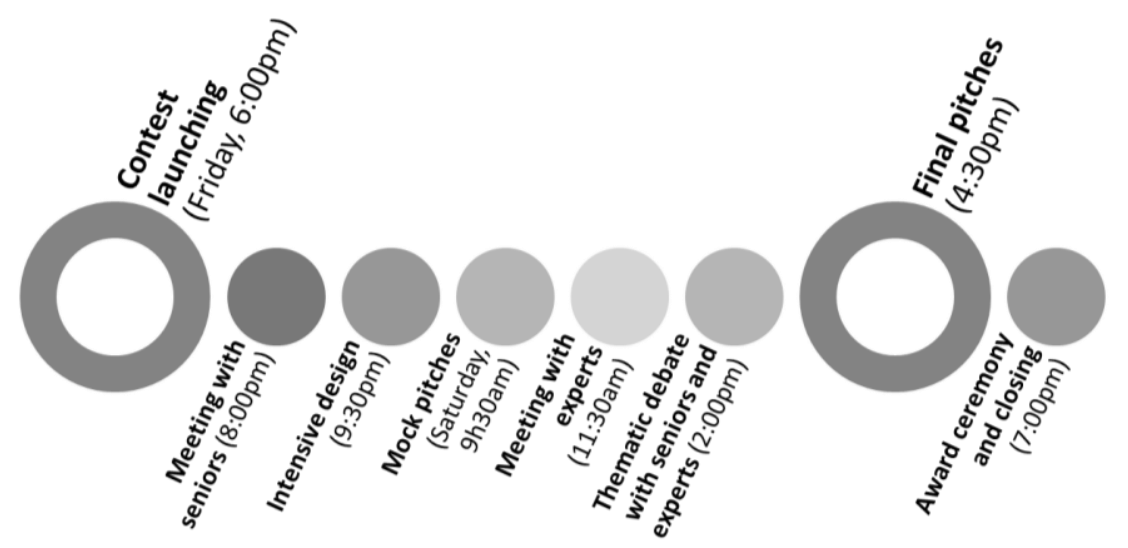

Figure 1. Detailed process of the Silver Awards 2018

The Silver Awards 2017 were also held in November with a similar process. The contest starts on a Friday evening and ends on the following Saturday evening. One may notice that the seniors take an active part at different moments of the contest. First, the students meet some representatives of the seniors at the very beginning of their work (Friday evening). This is a free discussion where the students have the possibility to interview some of the seniors about their habits, needs, feelings. Second, on Saturday morning the groups of students give a mock oral pitch face to some experts and seniors (each senior attends to 5 pitches), in order to gain feedbacks and adapt their offer for the final pitch. Third, at the beginning of the afternoon, thematic debates are organized with experts and seniors to help the student finalizing their proposal. Finally, the final pitches are organized at 4:30 pm on Saturday evening with two modalities:

1. The ten groups of students give a pitch of their proposal during one minute and a half, in front of all the jury members (experts and seniors);

2. Then the jury members are divided into 5 juries; each group of students spends 8 minutes with each jury; they give a more detailed presentation during 3 minutes, then they answer to the jury's questions during 5 additional minutes. Each group can provide some tangible elements to the jury members such as physical prototypes, UX mock-ups, printed leaflets, printed business model canvas...

During these two moments, the jury members (both experts and seniors) evaluate the ten projects with an assessment grid (explained in the next section). After the evaluation, votes are counted, and a ranking of the projects is made. The three best projects are awarded.

Table 1 summarizes the keys figures and thematic areas of the 2017 and 2018 editions of the Silver Awards. In both cases, 30 students are divided in ten teams of 3 with mixed educational backgrounds (disciplines and institutions). The design brief for the students is very simple: "Designing, in less than 24 hours, a product, a service, an activity, a place... at the service of the (autonomous or weakened) seniors' longer life expectancy and/or their family circle". The only constraint for each group is to propose an offer for one of the four or five thematic areas defined each year (see last column of Table 1).

The 16 to 18 seniors recruited each year are identified through the help of Silver Valley network members (such as insurance companies, social security agency or providers of residencies for seniors, but also associations of senior citizens). Each year, the organizers try to improve the representativeness of the panel of seniors compared to the French population. In 2017, the panel mainly included upper social-professional category people; while in 2018 the panel has been more open to broader categories. Beyond being only "seniors", all of them had of course a professional career in the past (or in the present as some of them are not retired) with a high variability of 
professional skills and jobs, such as company directors, teachers, medical staff and workers. They are aged from 60 to 86. The turnover of new seniors joining the panel is about $50 \%$ between 2017 and 2018.

Table 1. Recapitulation of the two last editions

\begin{tabular}{|c|c|c|c|c|c|}
\hline Year & $\begin{array}{c}\text { Number } \\
\text { of } \\
\text { students }\end{array}$ & $\begin{array}{c}\text { Number } \\
\text { of } \\
\text { projects }\end{array}$ & $\begin{array}{c}\text { Number } \\
\text { of } \\
\text { seniors } \\
\end{array}$ & $\begin{array}{c}\text { Number } \\
\text { of } \\
\text { experts }\end{array}$ & $\begin{array}{l}\text { Thematic areas } \\
\text { (related projects) }\end{array}$ \\
\hline 2017 & 30 & 10 & 18 & 22 & $\begin{array}{ll}\text { - } & \text { Apprehension of retirement }\left(A^{17}, E^{17}\right) \\
\text { - } & \text { Help from family circle }\left(B^{17}\right) \\
\text { - } & \text { Seniors' activities }\left(C^{17}, G^{17}\right) \\
\text { - } & \text { Shopping in supermarkets } \\
& \left(D^{17}, F^{17}, J^{17}\right) \\
\text { - } & \text { Seniors' free time solicitation } \\
& \left(H^{17}, I^{17}\right)\end{array}$ \\
\hline 2018 & 30 & 10 & 16 & 16 & $\begin{array}{ll}\text { - } & \text { Taking care of pets }\left(A^{18}, G^{18}, I^{18}\right) \\
\text { - } & \text { Accessibility of urban and rural } \\
& \text { spaces }\left(C^{18}, D^{18}\right) \\
\text { - } & \text { Informed shopping }\left(B^{18}\right) \\
\text { - } & \text { Daily life organization } \\
& \left(E^{18}, F^{18}, H^{18}, J^{18}\right)\end{array}$ \\
\hline
\end{tabular}

The next section details the assessment grid proposed to both the innovation experts and the seniors, as well as the methodology used to analyse the results proposed in Section 5.

\section{METHODOLOGY}

The assessment grid used by the jury was initially inspired by the UNPC model described in section 2.3. From the first edition of the Silver Awards, the organizers chose to adapt this model to help the jury members, especially the seniors, to understand the criteria in a short time. One may notice for example that the concept of desirability, popularized by IDEO (2015) has been introduced as the organizers have observed that lots of products in the Silver Economy are useful in term of delivered services, even if elderly people reject them.

For the Silver Awards 2017 and 2018, the same assessment grid with five criteria was used (Table 2).

Table 2. Definition of the 5 evaluation criteria

\begin{tabular}{ll}
\hline Name & Definition \\
\hline Usefulness & $\begin{array}{l}\text { Relevance of the identified needs } \\
\text { Real improvement for users/customers }\end{array}$ \\
\hline Credibility & $\begin{array}{l}\text { Feasibility of the implementation } \\
\text { Potential of the business model }\end{array}$ \\
\hline Desirability & $\begin{array}{l}\text { Attractiveness of the solution to recommend it, buy it or use it } \\
\text { Quality of the arguments and the presentation materials }\end{array}$ \\
\hline Concreteness & $\begin{array}{l}\text { Tangibility of the presentation and the arguments } \\
\text { Structuration of presentation materials }\end{array}$ \\
\hline Newness/Ingenuity & $\begin{array}{l}\text { Strong differentiation from the existing solutions } \\
\text { Improvement of the existing solutions }\end{array}$ \\
\hline
\end{tabular}

Several prompting questions are added to the descriptions. For example, for "Usefulness" questions are: "Are the future users well identified?"; "Is the solution in line with habits and needs of users?"; "Would you buy it, for yourself of one of your relatives?". Each member of the jury evaluates each project on a 4-point Likert scale from 0 to 3 in 2017 with the following meaning: $0=$ not at all; $1=$ weakly; 2 = moderately; $3=$ absolutely. A total grade for each project is then calculated as the sum of the 5 criteria grades. Organizers of the contest chose to extend this Likert scale from 0 to 4 in 2018 to enable a more detailed assessment by jury members. 
Figure 2 shows an excerpt of the assessment grid provided to the jury members in 2018 (both experts and seniors). It is included in an evaluation guideline provided to the jury members, along with the detailed process and organization of the Silver Awards, the definition of the 5 evaluation criteria, the definition of the 5-point Likert scale used to assess each criterion, as well as a glossary giving the definition of some concepts such as Design, Innovation or Business Model. A briefing session is organized with the seniors a few days before the event, where the criteria are explained and discussed. Also, before the final pitches during the Silver Awards, the criteria are recalled.

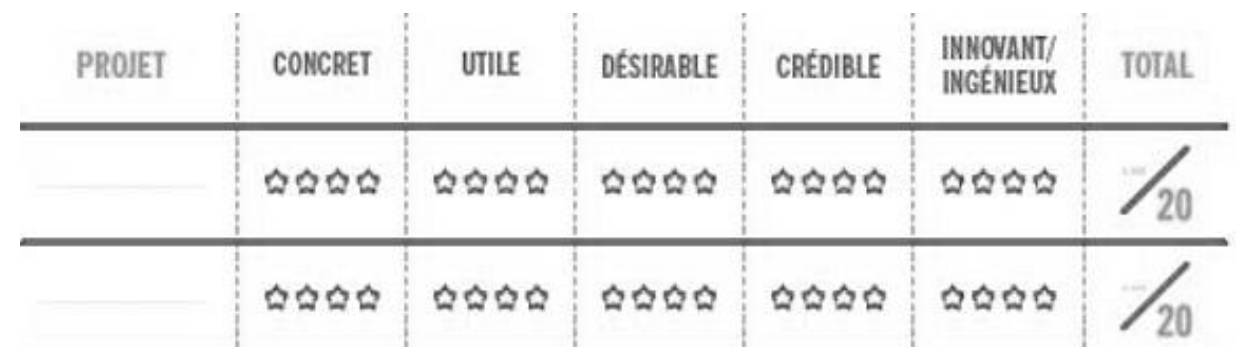

Figure 2. Overview of the assessment grid used during the Silver Awards 2018

It is important to notice that the authors of this paper were not involved in the definition of this assessment grid. They were only observers in the Silver Awards 2017 and 2018. Based on this evaluation process, the methodology consists in collecting the data provided by the jury members during the final pitches and to process them to observe the variability of the votes between the seniors, between the experts, and between the seniors and the experts. The analysis is based on normalized mean votes, ordinal ranking of the projects, standard deviation and correlation by population (experts and seniors) for each criterion and each project. The most interesting results are explained in Section 5.

\section{RESULTS}

\subsection{Vote results}

Seniors and experts had to grade the 10 projects (labelled A to J) in terms of 5 criteria on a 4-point Likert scale in 2017 and a 5-point Likert scale in 2018. A total grade of each project is calculated as the sum of these 5 criteria grades. In order to compare the 2017 and 2018 year, the results presented in this section are normalized, to have values comprised between 0 and 1. Figure 3 and 4 compare the 10 projects graduated by the jury in 2017 and 2018. Total grades for the seniors the experts are also detailed for each project. The vertical axis represents the total grade of the projects normalized between 0 and 1 .

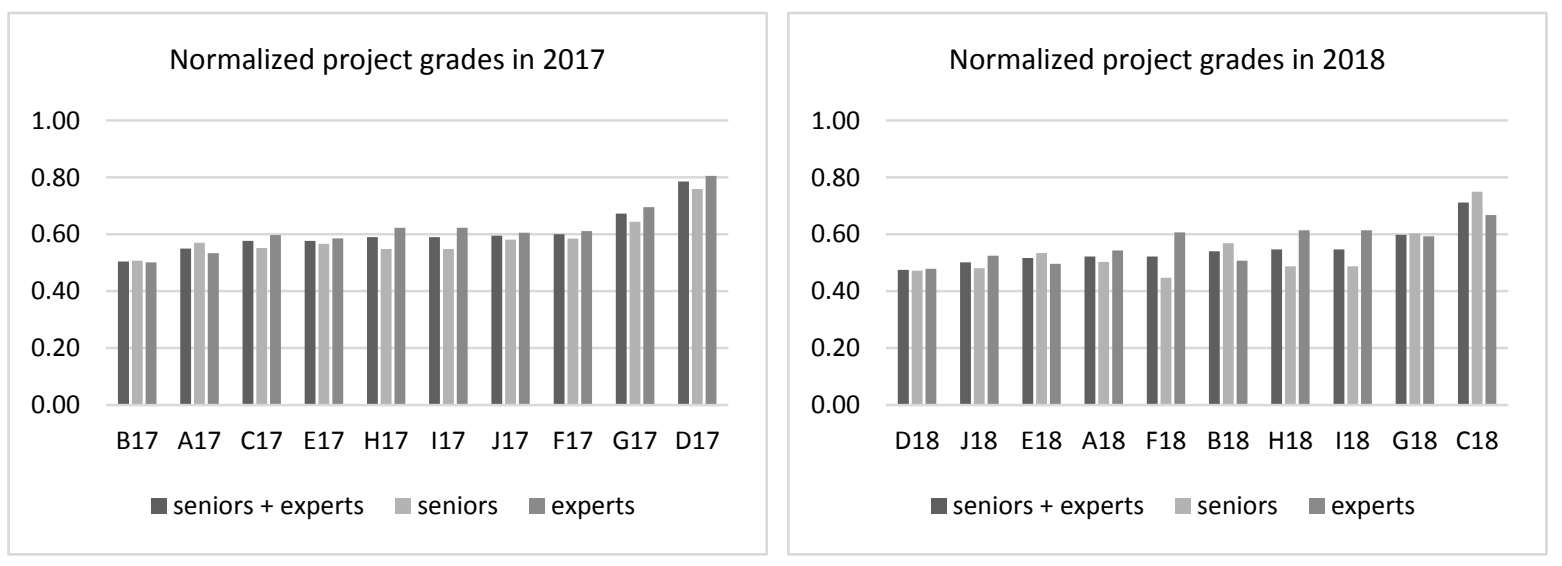

Figure 3 and Figure 4. Normalized project grades of the jury (left: 2017, right: 2018)

As a first remark, one can see that there is a slight difference between the expert and senior grades and that all projects are evaluated between 0,48 and 0,81 . Also, the best-graduated project $\mathrm{G}^{17}$ and $\mathrm{D}^{17}$, and $\mathrm{C}^{18}$ stands out from the others. Standard deviations of each criteria for both seniors and experts in 2017 and 2018 were calculated and presented very few differences, ranging from 0,227 to 0,251 (2017); 0,193 to 0,248 (2018). This means that the dispersion of the grades looks similar between the votes of the seniors and the ones of the experts. 


\subsection{Correlation between the senior and the expert votes}

In order to get an estimation of the relation of the project evaluation by the experts and the seniors, the $\mathrm{R}$-squared coefficient was calculated. R-squared is a statistical value used to assess a possible linear association between two variables.

Figure 5 presents 2 graphs. As, in the end, only the top projects are awarded, we found interesting to present the projects in term of calculated ranking. The two graphs map the 10 projects in 2017 (left) and 2018 (right) in term of ranking. Ranks were calculated from 1 to 10 corresponding to projects arranged in ascending order (from the lower grade to the higher one). Each project has a senior rank and an expert rank. For example, project $\mathrm{A}^{17}$ has a rank of 2 by the experts (vertical axis) and 6 by the seniors (horizontal axis). The corresponding R-squared is presented in each graph, but also in Table 3 . This table shows the R-squared values between the two populations of assessors, for the project grades and project rankings, for 2017 and 2018, for the total scores but also criterion by criterion.
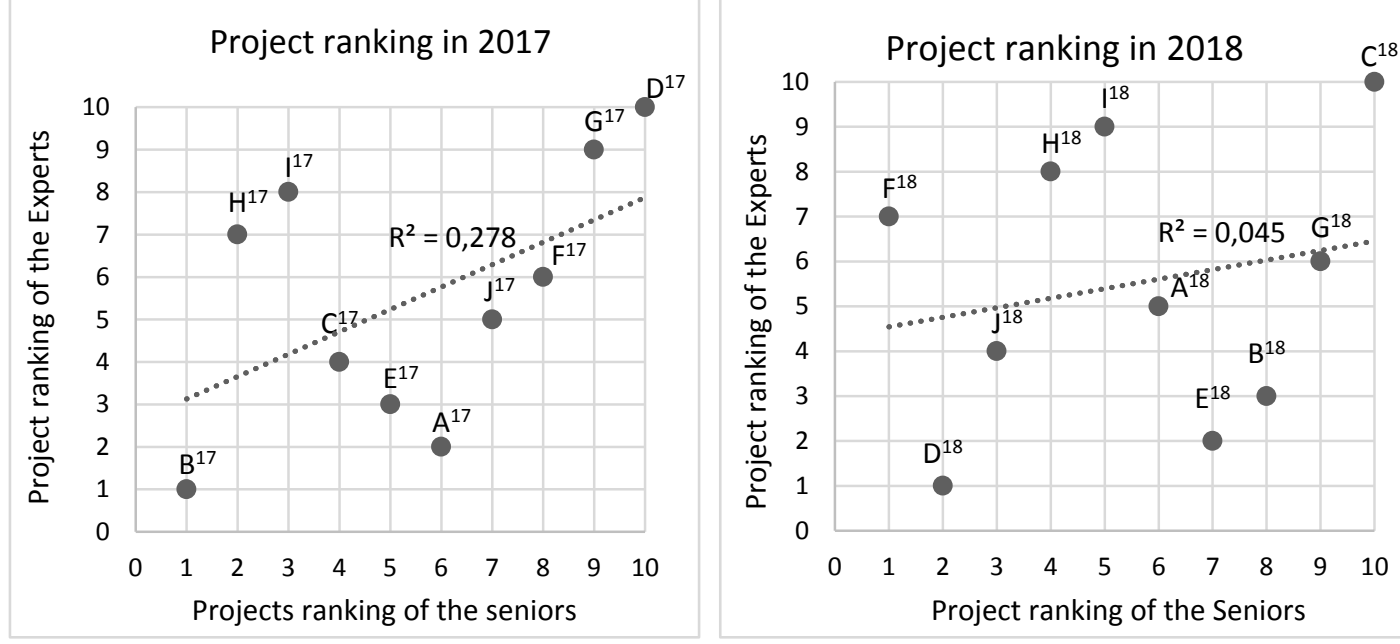

Figure 5. Project mapping in term ranking for seniors and experts in 2017 (left) and 2018 (right)

Table 3. R-squared evaluations (grade and rank) in 2017 and 2018

\begin{tabular}{lcccc}
\hline & \multicolumn{2}{c}{2017} & \multicolumn{2}{c}{2018} \\
\cline { 2 - 5 } & Project grade & Project ranking & Project grade & $\begin{array}{c}\text { Project } \\
\text { ranking }\end{array}$ \\
\hline Usefulness & 0.558 & 0.405 & 0.528 & 0.503 \\
\hline Credibility & 0.804 & 0.905 & $<0.001$ & 0.023 \\
\hline Concreteness & 0.723 & 0.905 & 0.312 & 0.155 \\
\hline Desirability & 0.315 & 0.218 & 0.012 & 0.096 \\
\hline $\begin{array}{l}\text { Newness/Ingenuit } \\
\text { y }\end{array}$ & 0.863 & 0.730 & 0.436 & 0.241 \\
\hline Total & $\mathbf{0 . 8 3 5}$ & $\mathbf{0 . 2 7 8}$ & $\mathbf{0 . 1 8 9}$ & $\mathbf{0 . 0 4 5}$ \\
\hline
\end{tabular}

$(\mathrm{R}$-squared $>0,7) \quad(0,7>\mathrm{R}$-squared $>0,4) \quad(0,4>\mathrm{R}$-squared $)$

As a first remark, one can see that only in 2017, projects are correlated between the experts and seniors in term of grades ( $\mathrm{R}$-squared $=0,835)$. In all the other case (project grade in 2018 and project ranks in 2017 and 2018), projects are not correlated between the experts and seniors (R-squared $<0,3$ ). As a second remark, one can notice that in 2017 and 2018 , the best projects $D^{17}$ and $C^{18}$ respectively are ranked at the highest position both for the experts and the seniors. Conversely, an opposite ranking is obtained between experts and seniors for projects $\mathrm{A}^{17}, \mathrm{H}^{17}, \mathrm{I}^{17}$ in 2017 , and $\mathrm{B}^{18}, \mathrm{E}^{18}, \mathrm{~F}^{18}$ in 2018.

Table 3 shows that in 2017, both in term of grade and ranking, project evaluations by seniors and experts are correlated (R-squared > 0.7) for the credibility, concreteness and newness/ingenuity criteria. Concerning usefulness, evaluations are less correlated $(0.7>\mathrm{R}$-squared $>0.4)$. Concerning desirability, evaluations are very poorly correlated (0.4 > R-squared). In 2018, only for usefulness (in term of grade and ranking) and newness/ingenuity (in term of grade), evaluations are moderately 
correlated $(0.7>\mathrm{R}$-squared $>0.4)$. For all the other cases in 2018, project evaluations are very poorly correlated $(0.4>\mathrm{R}$-squared). No clear correlation is noticed between the thematic areas of the projects (see Table 1) and their evaluation or ranking.

The next section presents a discussion and recommendations to ensure the relevance of evaluation innovative projects.

\section{DISCUSSION AND RECOMMENDATIONS}

Reflecting upon the differences in grades and ranking - Values of the vote grades are in a small range from 0.48 for the lowest evaluated project to 0.81 for the highest one. There are very few changes of this range between 2017 and 2018 even though the Likert-scale was extended. The standard deviation is also similar for both years and both jury panels. As in the end, only the best projects win prices, we found interesting to calculate the R-Squared value based on the project ranks. Results shows that experts and seniors evaluations are highly different except for the best project which is the same. We can make the hypothesis that seniors might judge a project based on their previous work, personal experiences and history of users, and emotions meanwhile expert might judge the project with their experiences and expertise with less personal projections. Therefore, the evaluation grades are different. This point can be reinforced, as we can see that, in 2017, only the desirability criterion has a very low correlated score.

In further work, the authors will elicit more properly a list of hypotheses on assessment discrepancy between the two groups (inter and intra-group) and derive the appropriate p-values. For instance, an hypothesis would be: "Is there a difference on criterion $\mathrm{X}$ between groups $\mathrm{X}$ and $\mathrm{Y}$ ?"

Explanatory factors for (un)correlations

We can make hypotheses on factors that account for dissimilar ranking: the theme of project, the realism of prototype or mock-up, the sensitivity of the senior to technology, the profile of the senior (correlated with social inclusion and partly correlated with age).

R-squared values between 2017 and 2018 are very different. There are several parameters that might explain this fact: students, thematic areas, coaches, experts and seniors jury members. Some of the coaches and jury members were the same in 2017 and 2018. A learning effect might be taken in account in addition to the singularity of each of them. As recommendations, we can suggest continuing to incorporate seniors in the jury process because their voices are different from the experts' ones and they are thought to be experts of their own life, but in trying in addition to get more information on who they are (see senior profiles (Silver Valley, 2018)).

Practical recommendations for future sessions - In a detailed analysis to come, we will study intergroup (experts/seniors) and intra-group preference dissimilarities. In addition, we will also statistically assess the significance of some hypotheses like "Is Usefulness criterion more understood by seniors than experts?" Finally, linking seniors' evaluation with their past experience, degree of autonomy, motivation, previous experience in project evaluation could be enlightening. We can also suggest to differentiate criteria that should be applied to seniors and to experts. Indeed, we do not know if it is useful that seniors judge the credibility of a project because, in the end, it is the duty of experts to judge the economic potential of a project. With regard to usefulness, it could be valuable to reflect more specifically upon the five areas of interest for seniors pointed out in Wikberg-Nilsson et al. (2018): keeping family together, enjoying life at home, being close to nature, self-development and promotion of conditions for healthy ageing. A co-designed set of criteria between seniors and experts, prior to each contest, could be a way to strengthen the evaluation process.

Also, we advocate for an evolution of the jury process: more precisely staff between seniors and experts (with identified competences); balance senior profiles (at least record their profiles); if there is enough time between evaluation and results, process the grades, ranking and organize a discussion between all jury members for projects with dissimilar ranking.

\section{CONCLUDING REMARKS}

This paper is a first attempt to analyse the inclusion of elderly people in an innovation jury. Based on the outcomes of two innovation contests, results show that the elderly are able to provide consistent votes but they are not necessarily following the same trends than the innovation experts of the same jury. The main perspective of this work is thus to study if the judgement of the seniors is relevant when assessing innovative offers; if yes, including seniors in an innovation jury for the Silver Economy would undoubtedly enrich the process; if not, several leads exist in the literature to make their evaluation more robust. To do so, 
the authors will continue the present work by analysing a new set of data of a Silver Economy start-up challenge held in 2016, where 8 start-ups pitched their project in front of 8 juries exclusively composed of elderly people. The current state of success or failure of these entrepreneurial projects - 2 years after the challenge - compared to the elderly's judgements should bring valuable insights to assess the relevance of their votes.

\section{ACKNOWLEDGEMENTS}

The authors gratefully thanks Silver Valley network and team, in particular Nicolas Menet and Lucile Picon for their helpful contributions and the access to detailed data allowing this work. This research work was carried out in the framework of the Technological Research Institute SystemX, and therefore granted with public funds within the scope of the French Program "Investissements d'Avenir".

\section{REFERENCES}

Astebro, T. (2004), “Key success factors for technological entrepreneur' R\&D Project”, IEEE Transactions on engineering management, Vol. 51 No. 3, pp. 314-321.

Boatwright, P., and Cagan, J. (2010), Built to Love: Creating Products That Captivate Customers, BerrettKoehler (Ed.), ISBN: 978-1605096988.

Brubaker, E., Reynolds, J., Carl, S., Sunday, S., Sheri, D. and Yang, M. (2017), "Co-design in Zambia - an examination of design outcomes", 21 st International Conference on Engineering Design (ICED 17), Vancouver, Canada, 21-25.08.

Buur, J. and Matthews, B. (2008), "Participatory innovation", International Journal of Innovation Management, Vol. 12 No. 3, pp. 255-273. https://doi.org/10.1142/S1363919608001996.

Cooper, R.G. (2001), Winning at New Products: Accelerating the Process from Idea to Launch, Basic Books (Ed.), 3rd edition, ISBN: 978-0738204635.

Dean, D. and Santanen, E. (2006), "Identifying Quality, Novel, and Creative Ideas: Constructs and Scales for Idea Evaluation", Journal of the Association for Information Systems, Vol. 7 No. 10, pp. 646-699.

Euromonitor (2012), Boomers as Consumers. [Online]. Available at https://www.euromonitor.com/boomers-asconsumers/report (accessed 1/10/18).

European Commission (2015), Silver Economy, Active aging, Business Innovation Observatory.

INSEE (2014), Population par groupes d'âges quinquennaux, Available at https://www.insee.fr.

Jagtap, S. (2018), "Design and Poverty: A Review of Contexts, Roles of Poor People, and Methods", Research in Engineering Design, pp. 1-22. https://doi.org/10.1007/s00163-018-0294-7.

Klein, M. and Garcia, A.C. (2015), "High-Speed Idea Filtering with the Bag of Lemons", Decision Support Systems, Vol. 78, pp. 39-50. https://doi.org/10.1016/j.dss.2015.06.005.

Klein, M. and Garcia, A.C. (2015), "High-speed idea filtering with the bag of lemons", Decision Support Systems, Vol. 78, pp. 39-50.

IDEO (2015), Field Guide to Human-Centered Design, IDEO.org.

Ruland, C.M., Starren, J. and Vatne, T.M. (2008), "Participatory design with children in the development of a support system for patient-centered care in pediatric oncology", Journal of biomedical informatics, Vol. 41 No. 4, pp. 624-635.

Sanders, E.B.-N. and Stappers, P.J. (2008), "Co-creation and the new landscapes of design", CoDesign, Vol. 4 No. 1 , pp. $5-18$.

Shah, J.J., Smith, S.M. and Vargas-Hernandez, N. (2003), "Metrics for measuring ideation effectiveness", Design Studies, Vol. 24, pp. 111-134.

Silver Valley (2018), Générations Séniors, report, Paris, France.

Wallisch, A., Maccioni, L., Trautmann, L., Ostermeyer, E., Borgianni, Y. and Borg, J.C. (2018), "Lessons learnt in designing transportation solutions for elderly people following a participatory approach", 15th International Design Conference DESIGN, Dubrovnik Croatia, May 21-24.

Wikberg-Nilsson, A., Normark, J., Björklund, C. and Wiklund Axelsson, S. (2018), "Healthcloud - Participatory design of user interfaces for senior people's active aging". NordDesign 2018, Linköping, Sweden, 14th - 17th August.

World Health Organization (2015), World report on ageing and health.

Yannou, B., Farel, R., Cluzel, F., et al. (2017), "The UNPC innovativeness set of indicators for idea or project selection and maturation in healthcare", International Journal of Design Creativity and Innovation, Vol. 5 No. 3-4, pp. 205-221.

Zsarnoczky, M. (2016), "Innovation challenges of the silver economy", Management, Vol. 28 No. 1, pp. 105-109. 